\title{
La figuración poética de la ruina en la última poesía de José Emilio Pacheco*
}

\section{The Poetic Figuration of Ruin in the Latest Poetry of José Emilio Pacheco}

Rosario Pascual Battista ${ }^{\text {a }}$

DOI: https://doi.org/10.11144/Javeriana.cl25.fpru

Universidad Nacional de La Pampa, Argentina

pascualbattista.rosario@gmail.com

ORCID: https://orcid.org/0000-0003-4496-6993

Recibido: 25 Septiembre 2019

Aceptado: 05 Julio 2020

Publicado: 20 Agosto 2021

\section{Resumen:}

El presente artículo estudia en Como la lluvia [2001-2008] . La edad de las tinieblas [2009] la imagen poética de la ruina como un modo de responder al paso inevitable del tiempo. La enunciación en ambos libros se sostiene en un yo poético que, mientras identifica un mundo cada vez más inmerso en la destrucción, percibe la proximidad de la propia muerte. La ruina, entonces, está atravesada por el tópico del tiempo como marca de destrucción y señal de muerte; pero, como lo analizamos en este artículo, el tiempo también posibilita, mediante el valor del instante, contrarrestar ese mundo en ruinas y rescatar el valor de la poesía.

Palabras clave: José Emilio Pacheco, poesía, México, ruina, tiempo.

\section{Abstract:}

This article aims to study the poetic image of ruin as a way of responding to the inevitable passage of time in Como la lluvia [2001-2008] and La edad de las tinieblas [2009]. The enunciation in both books is based on the authorial voice that perceives the proximity of his own death, while identifying a world increasingly immersed in destruction. Ruin, then, is crossed by the topic of time as a mark of destruction and a sign of death. However, as we analyze in this article, time also makes it possible, through the value of the instant, to counter that ruined world and rescue the value of poetry.

Keywords: José Emilio Pacheco, poetry, Mexico, ruin, time.

Desde el inicio de su labor como poeta, podemos identificar la preocupación de José Emilio Pacheco (México, 1939-2014) por hilvanar los vínculos entre la imagen poética de la ruina, lo perdido, el pasado y el poeta, quien resguarda el espacio distintivo de la memoria poética. ${ }^{1}$ A través de sus diferentes libros, este tópico adquiere matices distintivos o particulares que van desde ceñir lo ruin en un contexto más bien universal, sin delimitaciones específicas, hasta, como ocurre en el poemario El reposo del fuego [1963-1964] y con claridad en Miro la tierra [1983-1986], presentar lo destructivo a partir de hechos precisos de la historia mexicana, marcados por la violencia, como la Conquista española, y episodios trágicos, como el terremoto ocurrido en la ciudad de México en el año $1985 .^{2}$

En este trabajo nos ocupamos de los textos correspondientes a la última parte de la producción poética de José Emilio Pacheco y pretendemos demostrar que no están vinculados con la respuesta a un hecho histórico en particular, sino, más bien, que apelan a un reposicionamiento del yo poético que percibe, además de un mundo cada vez más inmerso en la destrucción y la desintegración, la inminente presencia de la muerte. Sostenemos que en la última poesía del escritor mexicano identificamos signos que dan cuenta no solamente del fin de un proceso de destrucción, sino también de la constitución de un yo poético a partir del escenario de la propia muerte. La enunciación poética, entonces, se sostiene sobre un tono que fusiona la melancolía, resultado de un pasado irrecuperable, y la reflexión apocalíptica por el inevitable arribo del final de la vida. El tiempo, constante preocupación de la poética pachequiana, se presenta en los poemarios Como la lluvia [2001-2008] y La edad de las tinieblas [2009] como una marca de destrucción, pero también como un

Notas de autor

\footnotetext{
a Autora de correspondencia. Correo electrónico: pascualbattista.rosario@gmail.com
} 
generador de instantes de belleza y allí es donde la poesía se forja como un lenguaje posible que permite retener los momentos, aunque fugaces, felices.

\section{Poetizar desde la ruina: sobre la figuración de la muerte}

Es posible comenzar a estudiar la modulación de la imagen poética de la ruina en la última producción de José Emilio Pacheco a partir del epígrafe que aparece al comienzo de Como la lluvia [2001-2008], el cual es una traducción de "Consolación a Lucilio" de Séneca. La particularidad de dicha traducción es que José Emilio Pacheco no se la atribuye a sí mismo, sino a un poeta mexicano llamado Julián Hernández - ya mencionado por el autor en otros poemarios, específicamente en la sección "Apéndice: Cancionero apócrifo" de No me preguntes cómo pasa el tiempo [1964-1968]-. Se trata de un heterónimo, de una máscara poética, a quien Pacheco le inventa una biografía creíble que tiene puntos de contacto con su propia vida. Así, los versos de Hernández, quien se inclinó, como Pacheco, por la carrera de derecho, "intentan y a veces logran expresar poéticamente la amargura sarcástica de un perpetuo excluido que contempla la vida literaria, y la existencia toda, con quebrantada y a la postre estéril ironía" (103). Como podemos observar, ya el epígrafe introduce, mediante una voz poética en primera persona del plural, la temática de la muerte. Frente a un mar que, a pesar de su fluidez, es turbio y hondo, el hablante lírico no puede escapar del vaivén de las olas; la imagen de un naufragio permanente concentra la imposibilidad de controlarlas y lograr un equilibrio: "Chocamos unos contra otros y naufragamos a veces" (608). Los "habitantes" de este mar impetuoso aparecieron en él porque fueron "arrojados" (608), es decir, contra su voluntad, fueron expulsados hacia un lugar donde "jamás pondremos pie en tierra firme" (608), hacia donde, inevitablemente, "el único puerto seguro es la muerte" (608). El yo lírico está, como sus compañeros, involucrado en este trágico final, en el desenlace que, tarde o temprano, llegará y está señalado por el destino, debido a que "contra eso no hay ni puede haber resistencia" (686). Nada ni nadie puede contra el arribo de la muerte y el epígrafe que inaugura el poemario gira en torno a las posibilidades de sobrevivir del poeta frente a un desenlace que, aunque irrevocable, puede llegar a encontrar en la poesía una posibilidad de amparo y salvación.

"El vecino de arriba", otro de los poemas incluidos en Como la lluvia [2001-2008], se abre con una cita de La vida es sueño de Pedro Calderón de la Barca y ya aquí encontramos cómo la muerte, inevitable e inexorable, rodea el texto mediante las descripciones que el yo lírico realiza de la "vida", marcada por la desdicha y por una constante anticipación de la muerte, enfatizada en la precisión de ese vecino que "vive preso" (617) y en los verbos que acompañan cada una de sus acciones. Estos, lejos de señalar una vida reconfortante, sostienen, como dice el verso final del poema, "el crimen sin nombre de haber nacido" (618). El encierro, en efecto, se manifiesta en una desesperación, en aumento, que oprime tanto a su habitante como al poeta, cuyas descripciones, ancladas en un lenguaje directo y conciso, se disponen en un orden que encuentra su clímax en el lamento incesante:

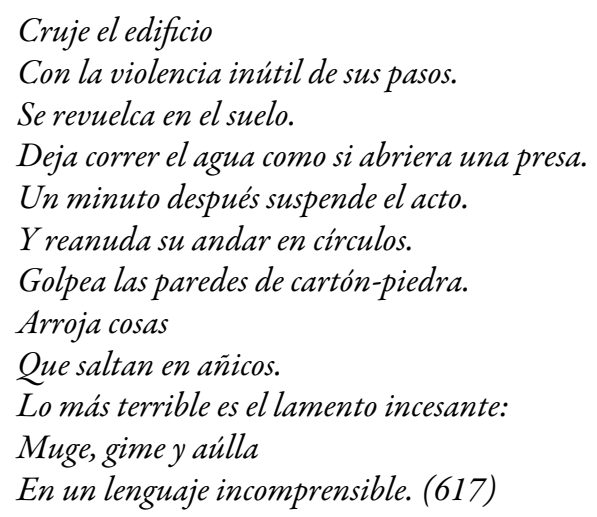


El poeta se posiciona desde el lugar de la compasión de ese otro que no tiene otra salida que la muerte; los días perpetúan la rutina aciaga que el yo lírico siente como propia. La afición de su vecino también es la suya y, en efecto, el insalvable destino del otro es también el del sujeto: "Pasan semanas y el estruendo crece. / Se hacen más dolorosos los aullidos" (618).

La apropiación de ese destino por parte del poeta se hace más clara y se profundiza en el siguiente poema, "Galeotes", en el cual el tema del viaje y el naufragio recuerdan el epígrafe que abre el libro. Todos somos navegantes de un "viaje inmóvil" (618) porque "la cadena que llevamos / Nos ata en la desgracia" (619). A diferencia del poema anterior, en el que el uso de la tercera persona del singular parecía, en un primer momento, mantener un distanciamiento entre el tópico de la muerte y el poeta, en este caso, el uso de la primera persona del plural ("nosotros") acentúa el drama en el que también es protagonista el yo lírico porque hay una apropiación, una aceptación que ya es revelada en la primera estrofa:

\author{
De las formas de infierno \\ Diseñadas en este mundo \\ Para hacer indeseable la existencia \\ La más amarga es nuestra condena. (618)
}

En el título del poema se anuncia la definición que durante el desarrollo de la expresión poética se especificará e intensificará a partir de caracterizaciones que no hacen más que ceñir el tormento del que es víctima el hombre, el poeta. La puntuación cobra protagonismo porque circunscribe un ritmo discontinuo que transmite la pesadumbre de cargar con un destino irreversible, definido en la concatenación de cuatro términos que se articulan como sinónimos de muerte: "Todo lo compartimos: el martirio, / La sed, el calor y la desesperanza” (619). La muerte se convierte en un colectivo; inexorablemente, implicará la caída, nadie se salva del desastre, de esa "prisión flotante" (619). En efecto, esta última parte de la producción lírica de Pacheco comienza a mostrar las marcas de una muerte inmediata que se acerca a una "autobiografía de la muerte" (Kamenszain 77). ${ }^{3}$ Desde este cambio en el modo de tratamiento de la muerte es que podemos entender el tono diferente que manifiesta la poesía última de José Emilio Pacheco; una poesía más desesperanzadora, apocalíptica y sostenida por un yo lírico que se encuentra cada vez más solo, debido a que reconoce que "la muerte de un galeote no conmueve a los otros" (619). A partir de la segunda parte del poemario "Como si nada", "lo que se está por terminar" (Kamenszain 77) se revela mediante el laconismo del mensaje de cada uno de los poemas para insistir en la brevedad de la existencia humana; una existencia que no se arraiga en el presente porque siempre está pendiente del mañana, del supuesto bienestar de la posterioridad. En el ansia que tiene el yo por el final residiría el corolario de toda una existencia, resignada y sacrificada, por un mañana que, sin embargo, desilusiona y desalienta: "Tendrían que decirme si de verdad / Todo este horror de ahora era el Mañana” (636). No hay redención, sino la confirmación de que la existencia es una sucesión de horrores. La presencia de la primera persona se manifiesta porque el yo no solamente es testigo de su propia muerte, sino que también participa en su preparación. Frente a ese destino insalvable, el yo lírico reniega de ese sino, pero, vencido, prepara el que será su cadalso:

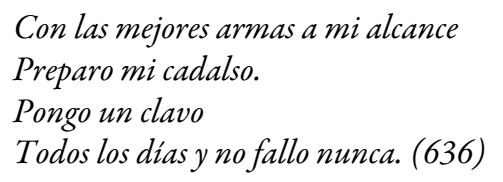

La apelación a la ironía, por momentos, intenta desdramatizar y descomprimir la tensión generada por la situación apremiante del final: "Tendrá su recompensa el gran esfuerzo. / La ejecución será una obra maestra. // Se invita al público / A escoger desde ahora sus lugares” (636). Sin embargo, en el poema siguiente, la muerte desenmascara muestra la naturaleza humana, los años de tormento; la muerte, en consecuencia, saca a la luz lo peor del hombre; la miseria, lo que se quiso ocultar. Pacheco reconoce una ética en la muerte que 
hace iguales a los seres humanos; la muerte se convierte no solamente en un desenlace inevitable, sino que desmonta antiguos privilegios e indultos "para mirarnos como somos" (637). ${ }^{4}$

Hay un frente a frente con la muerte, donde el poeta se siente despojado, desnudo, porque "la extrañeza", tal como se titula uno de los poemas de Como la lluvia [2001-2008], se apodera de todo, hasta el punto de que existe una despersonalización desde el momento en que el yo sabe que su llegada supuso reemplazar a otro y que, irremediablemente, su partida también implicará su sustitución. El poeta, parece decirnos la última poesía de Pacheco, se constituye desde la despersonalización porque desde su origen ocupa un lugar que no le pertenece definitivamente, que es momentáneo, debido a que, como su existencia, es fugaz y, hasta a veces, insignificante. Por eso, ese "sitio de alguien" (637) es un "inestable espacio" (637) que "consideramos algo natural" (638). No obstante, el hombre en esa extrañeza, en ese misterio de vivir en un mundo que lo despersonaliza, encuentra, paradójicamente, su humanidad. Hay, a lo largo de los poemas de esta última etapa, una construcción de lo humano, pero que, irremediablemente por su futilidad, al mismo tiempo que se constituye, se desarma, se desmorona y deja de ser. La omnipresencia de la muerte es lo que despersonaliza al yo que, en su intento de definirse, se presenta como algo que ya ha sido, como resto y ruina de algo que fue. Sin embargo, porque justamente es ruina y resto, puede enunciar su presencia, aunque inestable, en el poema. La existencia del poeta, entonces, se define a partir de esa paradoja; es necesario mostrar la anticipación de la muerte, del final ineludible, porque, a pesar de la despersonalización que supone, es la que da lugar a la realización de la obra poética; es verdad que todo va a desaparecer, no obstante, "las ciudades que se deshacen, los paisajes perdidos en las ventanas de las casas abandonadas, las personas muertas, siguen con nosotros gracias a la poesía como lugar de una memoria viva" (García Montero 11). En el mismo acto en que se reconoce la proximidad de la muerte, se reconoce la posibilidad de la poesía; es necesario, entonces, asumir "el terrible milagro de estar vivos" (Pacheco 638) para que, según Jorge Monteleone, un muerto pueda decir "yo" (61). ${ }^{5}$

La homonimia se constituye en un recurso retórico que sirve para figurar "la sagacidad de la muerte unánime" (Pacheco 638); en la presentación de las imágenes del mar y del río como espejo de la imagen del poeta se reconoce su "oficio solitario" (638): los ríos, tal como los poemas, "conocen la soledad mejor que nadie. / Fluyen a solas, van siempre solos" (638). El poema no conoce otra enunciación que no se produzca desde el desamparo y la soledad y la "Meditación del autobiógrafo" se corresponde con una reflexión en la que el poeta, cercado por la muerte, solamente halla preguntas sin ninguna respuesta. Los dos primeros versos son apelaciones a un tú ausente, mudo, que, en tanto desdoblamiento del yo, no hace más que multiplicar el vacío y la angustia que padece: “¿Con cuál ficción me quedo para no ver lo que soy? / ¿Qué otra mentira invento para justificar mi vacío?” (640). Este poema, pensamos, es el complemento de otro, cuyo título deja al descubierto desde qué lugar enuncia la voz poética: "Preguntas". Desde el misterio que sostiene el primer verso se enhebra la pregunta de la estrofa inicial, que se corresponde con las expresiones negativas del siguiente. Todo el poema, entonces, se ajusta a ese movimiento irresoluto, donde el yo interroga y el otro (que es él mismo) apenas balbucea una respuesta que se refuerza mediante adverbios de negación:

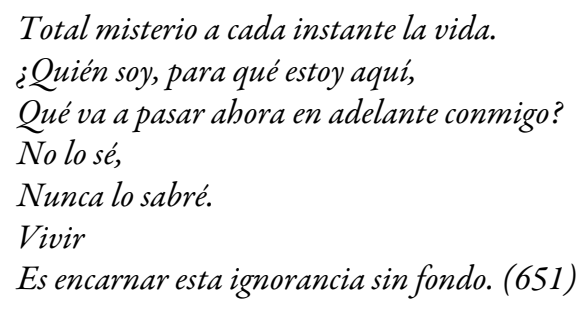

Una posible respuesta se encuentra en el poema "Una hoja”, que, en tanto metáfora de la escritura, lleva impreso el destino de quien, hastiado de la felicidad nimia, se propone, al menos, hacer del tópico de la ruina una forma de permanencia: 


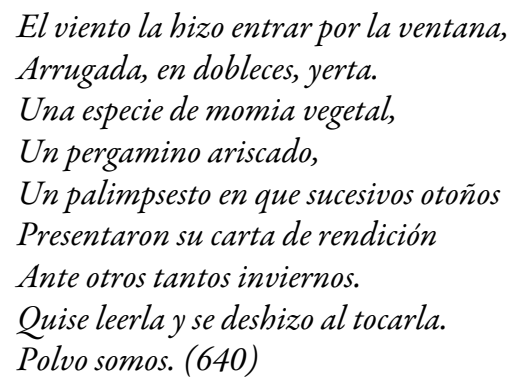

Nuevamente, como señalamos, es necesario presentar lo ruin y lo destructivo para que el poeta y sus poemas puedan tener presencia; puedan tener, como dicen los versos de "Tener o no tener", "la dicha que hoy nos cubre”, aunque, seguidamente, esta ya tiene los días contados (641).

Otro de los núcleos sugestivos que reconocemos, además de la soledad como el lugar de enunciación del yo lírico, es la autofiguración del poeta como excedente, como el mismo resto de una sociedad que no lo reconoce. Dice el poeta: "Al planeta como es / No le hago falta" (641). Su presencia no es la antítesis de su ausencia porque el planeta "proseguirá sin mí / Como antes pudo / Existir en mi ausencia" (641). La figura de la paradoja se muestra también en lo que el "afuera" pretende del poeta: lo invita a que se vaya, "en silencio" (642), cuando en realidad tampoco lo había invitado a llegar. Desde su insignificancia retiene, aunque efímera, su presencia. En este sentido, "Digo" se estructura sobre la paradoja de un decir que, inmediatamente, no dice. Sin embargo, en los intersticios de ese no decir, aparece la poesía. En los primeros versos de las estrofas surge la primera persona del singular que emplea el verbo decir, no obstante, a medida que avanza el poema se disipa ese yo enunciador que, al principio, parecía, exteriorizarse:

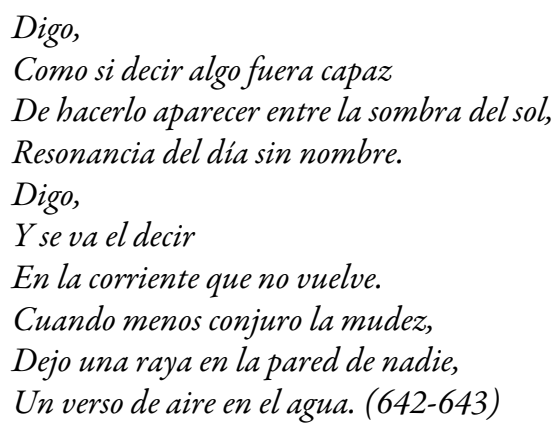

Los segundos versos de las dos primeras estrofas desdicen a ese yo que se muestra tan manifiesto en los primeros versos; incluso, al recuperar el verbo decir, la rectificación parece agudizarse. En la tercera estrofa, el último verso, a modo de oxímoron, agudiza aún más la instantaneidad del trazo del poeta; una instantaneidad, como dice otro poema, que, paradójicamente, también se desea que sea eterna: "Debería ser perpetua esa visión, / Debería / Iluminarnos para siempre" (648). La contigüidad de la vejez convierte a la muerte en lindante y esto provoca la vulnerabilidad de un yo que aspira a revalorar cada instante porque "cada momento / Vale más que ninguno anterior / Porque se sabe el último" (688).

Esta poética de lo inmediato de la poesía se complementa con otra de las características de la última producción de José Emilio Pacheco que aspira a colocar en primer plano los restos de la sociedad identificados, en este caso, con lo escatológico y lo "feo". Así, la poesía se convierte, a pesar de su instantaneidad, en un registro de los vestigios, ya no de una antigua época gloriosa, como pudo ser la precolombina, sino de aquellos que pertenecen a la cotidianeidad, al día a día de los hombres, a la "catacumba", como versa el poema "Melopea" (720), y donde el poeta reconoce el transcurrir del tiempo con respecto a los otros, porque afirma "soy por inmensa diferencia el más viejo" (720). De esta manera, plasma también que, en comparación con los otros, está más cerca de la muerte. Susana Zanetti afirma que un lenguaje duro y llano, complementado con imágenes abruptas e inmisericordes, pobló cada vez más los poemarios del escritor mexicano (35). Ese 
recrudecimiento, añadimos, se integra con la incorporación de esos restos de lo cotidiano, aquello que, a pesar de ser vivido con naturalidad, es convertido por la mirada del poeta en materia poética. La poesía, entonces, a pesar de sostenerse en la pronta caducidad en lo que apenas dicho ya se diluye, retiene, aunque sean desagradables, los restos de una sociedad que se desmorona:

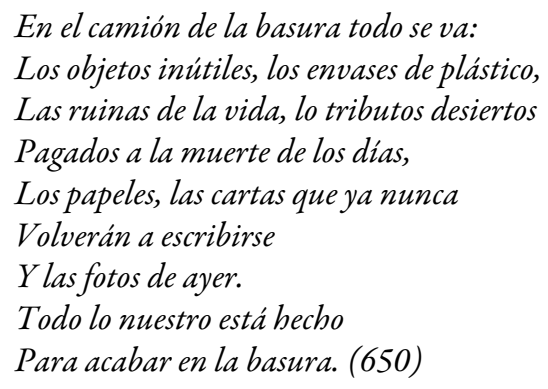

En algunos poemas, como es el caso de "Elogio del jabón", incluido en La edad de las tinieblas [2009], se recurre al recurso de la parodia para mostrar dicha "suciedad". La parodia, en tanto artefacto productor de textos (Jitrik 13), se sostiene en la intertextualidad; y la imitación, cabe señalar, es el elemento más básico de la intertextualidad. Sin embargo, como explica Noé Jitrik, la parodia no se queda en la pura imitación, sino que se libera de ella para adquirir cierta identidad textual, es decir, la parodia, en el acto imitativo, busca intencionalmente llegar a otra parte. A diferencia de la ironía, que consiste en un señalamiento evaluativo casi siempre peyorativo, Linda Hutcheon señala que la parodia, en tanto modalidad intertextual, no siempre se define como la oposición o el contraste entre dos textos, sino, tal como sugiere el prefijo griego para, 'al lado de', también indica un acuerdo y una intimidad (176-178). El acto imitativo "descansa sobre una cierta y muy especial inercia, mientras que la parodia supone una decisión" (Jitrik 14). En el caso del poema citado, Pacheco recupera un subgénero clásico, como es la oda, para resignificarlo. Recordemos, junto con Vicente Cristóbal, que la oda se relaciona en su origen con la música, porque nació para ser ejecutada al rimo de algún instrumento, por ejemplo, la lira, la cítara o la flauta, e, incluso, para ser acompañada de danza (22-23). Respecto a su contenido, este tipo de poesía, que tiene su origen en los antiguos líricos griegos (Alceo, Safo, Anacreonte y Píndaro), abarca un amplio abanico de temas, entre los que predomina el canto a los dioses, el encomio de héroes y atletas, el amor, el vino y los placeres del banquete (23). ${ }^{6}$ En el poema de Pacheco, tal como lo observamos en el título, el elogio o la celebración no va dirigido hacia un personaje o un suceso de alcance supraindividual (Cristóbal 20), sino a un objeto simple y cotidiano, como un jabón, el cual es mostrado, a modo de hipérbole, como "el objeto más bello y más limpio de este mundo" (Pacheco 739). Después, se prolonga esa primera caracterización, consolidada mediante un campo semántico vinculado con lo pulcro y lo impoluto, que resalta la candidez del objeto elogiado: "Trozo de nieve tibia o marfil inocente, el jabón resulta lo servicial por excelencia. Dan ganas de conservarlo ileso, halago para la vista, ofrenda para el tacto y el olfato" (739). Si, por un lado, se presenta la identificación de lo incorruptible, sostenido en la "virtuosidad" del jabón, por otro lado, se introduce su antítesis: "La sordidez del planeta" (739). El canto a la belleza y el aplauso a lo impoluto, arraigados en el instante fugaz donde se funden el jabón y el agua, son desplazados por los desperdicios que abundan en el mundo habitado: "Inocencia y pureza van a sacrificarse en el altar de la inmundicia. Al tocar la suciedad del planeta ambos, para absolvernos, dejarán su condición de lirio y origen para ser habitantes de las alcantarillas y lodo de la cloaca” (739). Dicha sordidez, a su vez, se identificará con México en el "Otro espejo" al homologar esta ciudad con la imagen de la mencionada cloaca, donde el poeta ubica tres palabras en mayúsculas que refuerzan dicha figuración: "Pestilencia del aire envilecido, Cloaca Máxima que ha devorado a México entero, descomposición unánime del planeta” (760).

Ahora bien, ¿por qué José Emilio Pacheco toma como objeto de su parodia una forma clásica? y ¿cuál es la intencionalidad que justifica esa elección? Como señalamos, junto con Jitrik, la parodia es un tipo de intertextualidad que implica determinadas interacciones. En este sentido, Pacheco ahonda sobre un tipo de 
texto que fue utilizado por algunos autores para alabar, por ejemplo, a figuras emblemáticas de la vida pública, tal es el caso de las odas del poeta latino Horacio (65 a. C.-8 a. C.) dedicadas a Augusto. Así, Pacheco efectúa una "torsión" del modelo clásico al introducir como tópico de su elogio un elemento que pertenece a la vida cotidiana, cuya caracterización, si en un primer momento se acerca al modo de decir "embelesado" de la oda, luego, se diluye al incorporar la visión particular del poeta sobre el hombre y el mundo donde reside. Es decir, estamos frente a una propuesta estética que desacralizaría y reformularía una de las convenciones del género. El elemento que fue honrado se arraiga, como el resto de las cosas que circundan a los hombres, en las corrupciones y en "la pesadumbre de ser" (739), porque es el responsable de limpiar "las señales de nuestra asquerosidad primigenia" (739). Lejos, además, se encuentra el destinatario idealizado y mediatizado por una relación de respeto; el poema de Pacheco incorpora una crítica al comportamiento humano atravesado por constantes actos de violencia, aludidos a través de una escena cotidiana del poeta:

Mientras me afeito y escucho un concierto de cámara, me niego a recordar que tanta belleza sobrenatural, la música vuelta espuma del aire, no sería posible sin los árboles destruidos (los instrumentos musicales), el marfil de los elefantes (el teclado del piano), las tripas de los gatos (las cuerdas). (740)

Lo desagradable y lo repulsivo se reúne en una forma poética que se distorsiona porque incorpora un contenido "inapropiado"; lo feo se coloca en el centro de esta nueva versión de la oda. Si vinculamos esta apropiación con el interés de José Emilio Pacheco por la tradición literaria y cultural que lo antecede, podemos pensar que esta operación paródica sobre este subgénero de la Antigüedad clásica se justifica también a partir de una de las intenciones que para Jitrik tiene la parodia. Pacheco, en su revisión, apropiación y alteración de la temática de la oda, presenta la escritura literaria como un espacio para definir ciertos enlaces y encadenamientos que distan de la inmovilidad, propia de una simple imitación. La parodia, entonces, puede ser leída en este caso como la continuidad de una tradición que se pretende recuperar y prolongar mediante el añadido de una temática diferente a la "establecida" por el modelo.

El mundo, como observamos, se convierte en un lugar peligroso para estar. El poeta se lamenta del universo en el que le tocó vivir y, en su canto, muestra su descontento: "Cuánta mudez / Del universo que me desampara" (655). Pesimista y melancólico, cree que no hay salvación en un mundo donde la muerte acorrala y el Mal, como dicen los siguientes versos, es el mundo mismo: "Gran enigma es el Mal. // Sobre este punto Dios guarda silencio / Y deja que hable el mundo en todo momento" (658). "Teatro del dolor", dice la voz lírica, porque en él habita "la vida cruel, absurda, inexplicable" (659). Los poemas, por su brevedad, se asemejan a los últimos quejidos del poeta, quien siente la muerte que lo cercena; sin embargo, esta nunca llega definitivamente, lo cual, lejos de suspender el padecimiento, lo recrudece: "El fin del mundo ya ha durado mucho / Y todo empeora / Pero no se acaba" (660). El poeta pertenece a la humanidad doliente, su destino no es otro que el de ser el objeto del microscopio que "me engrandece" (721). ¿Qué se alcanza a visualizar? Nada esperanzador: "La vida que se mueve siempre en combate. / Y en todas partes el dolor y el miedo" (721). Entre la permanencia que imprime el instante y el paso del tiempo, se configura una voz poética que se define desde los restos de un mundo que no encuentra la prosperidad. Su única posibilidad de realización está en la continuación de la propia destrucción; no hay oportunidad de cambiar el destino. El apocalipsis continuamente es anunciado en la última poesía pachequiana; de nada sirve el saber acerca del mundo porque este no alcanza para detener lo que vendrá; el yo lírico intenta, aunque sin éxito, descifrar la importancia de los conocimientos obtenidos. Nada es estable en una realidad que se define desde el caos y la intimidad con la muerte y, si la permanencia y la estabilidad existen, no es más que para reforzar que "el mapamundi actual es como el de antes / Una mancha feroz de fuego y sangre” (722). La mancha, como en este último caso, es una imagen poética que aparece en un verso final y, también, corresponde al título de uno de los poemas de Como la lluvia [2001-2008]; se manifiesta como obstáculo de un yo lírico que se quiere deshacer de ella, pero no puede. Nuevamente, aparece una voz enunciadora que declina, que se entrega, y esto se plasma en la sucesión de verbos que, separados por comas y sin conjunciones, acelera el inicio del poema: "Desisto, cedo, 
renuncio, abandono / Mi esfuerzo inútil, mi irrisorio afán" (724). Desprenderse de esa mancha se convierte en una empresa imposible; nada puede contra su eliminación: "He probado jabones, detergentes / Sustancias diseñadas contra el estrago. / Todo en vano: la mancha no se irá" (724). Reaparece la imagen de la sangre, metáfora de un crimen y de la muerte, cuyo significado, desde el desconocimiento, el poeta indaga:

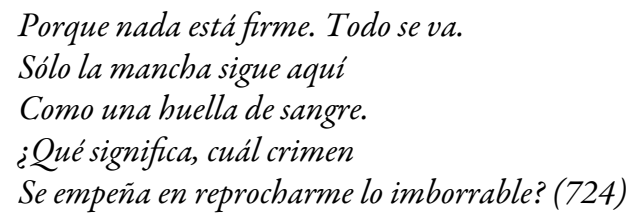

De acuerdo con José Ramón Ruisánchez Sierra podemos expresar que en esta poesía del autor mexicano "el bien sólo se vislumbra como horizonte, esto es, como imposibilidad; como un intento que fracasa" (156) debido a que el mal es estructural y amenaza, persigue y angustia al poeta, tal como lo observamos en la pregunta que cierra el poema. Los poemas de esta última producción literaria de José Emilio Pacheco se sostienen sobre el temor al arribo de la muerte; una muerte que es omnipresente y temida porque produce la rememoración de los males pasados y los convierte en pura presencia. La muerte, claro está, acecha siempre, pero con ella las ruinas, intactas, "son el monumento / Al estrago que fue y será mañana" (729). La poesía, en conclusión, se presenta como la expresión de lo que al poeta le preocupa; de ahí que la escritura se condense en un tono más apocalíptico y perturbador frente a una muerte que se avecina y que, en lugar de sosegar, intranquiliza al yo lírico, no lo libera de haber sido parte de un mundo marcado por la huella de la sangre:

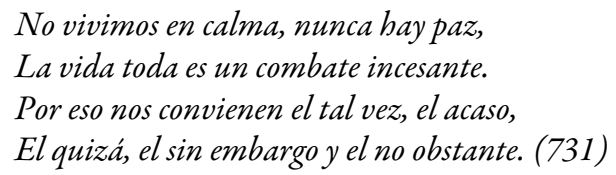

Este fragmento pertenece al poema "El lugar de la duda" y, tal como hemos ahondado en los poemas hasta aquí estudiados, es representativo de la posición que adquiere el yo lírico en los últimos poemas de José Emilio Pacheco. Por un lado, la incertidumbre, la perplejidad ante un pasado que no se puede cambiar y un futuro incierto porque, a pesar de la muerte, la "tierra saqueada" (736) persistirá. Y, por otro lado, la exacerbación de un yo, autodefinido como poeta, que nunca deja de ser sorprendido por el mundo en el que reside:

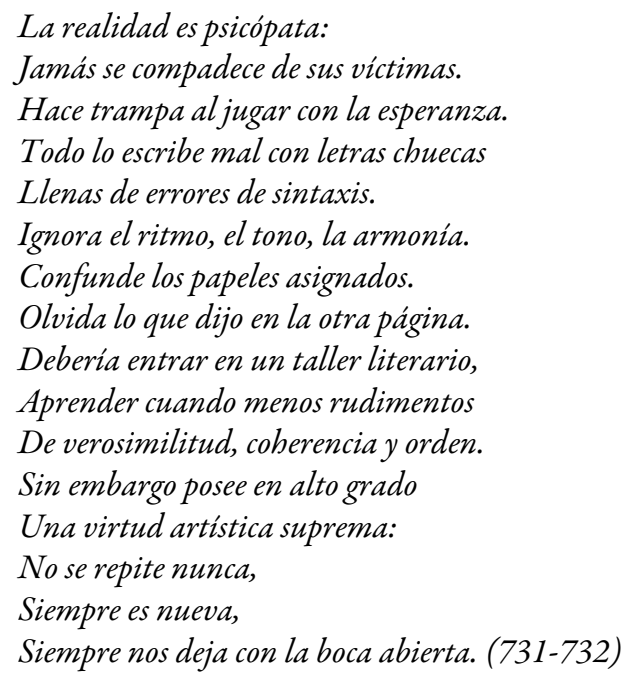




\section{Entre la muerte y la destrucción: el lugar de la poesía}

Tal como observamos, el tiempo es un tópico recurrente en la poesía de José Emilio Pacheco y es posible estudiarlo desde, al menos, dos perspectivas. Por un lado, como lo abordamos en el apartado anterior, su presencia como marca de la destrucción, como señal de la cercanía de la muerte y que, inevitablemente, lleva a la ruina y a la pérdida del hombre y su mundo. Sin embargo, en esta parte del artículo, nos centraremos en el otro aspecto que contiene el tópico del tiempo en esta producción lírica. En este sentido, es posible rastrear e identificar poesías donde la cuestión temporal se opone a esa primera imagen vinculada con el sentir apocalíptico del yo poético y, en consecuencia, se presenta la revalorización del instante como el momento de condensación de la poesía.

En los últimos años de la producción poética pachequiana se funden, entonces, estas dos maneras antitéticas de entender el tiempo; su poética se revela en esa paradoja desde la cual se entiende el tiempo. Pareciera que es necesario pensar la dimensión temporal desde la destrucción y la ruina que provoca para, así, revalorizar los momentos fugaces de la poesía. La primera estrofa de "Sombra de nieve" ubica en las imágenes del jarrón, las begonias y el ave la multiplicidad existente en el universo; un universo en constante transformación, en el que la fluidez y la metamorfosis de sus componentes se muestran "en lucha con la fijeza" (667). Sin embargo, es en la tercera estrofa en la que surge la posibilidad de la reunión y la comunión de todos los elementos diseminados mediante el lenguaje de la poesía; el lenguaje poético armoniza y conjuga la dispersión ocasionada, al mismo tiempo que da cuenta de la destrucción:

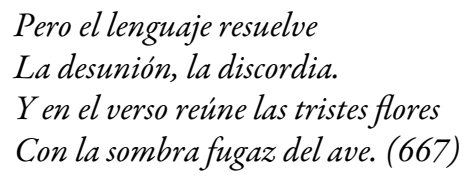

Si nos centramos en los últimos versos percibimos que en la expresión literaria, y en particular en la lírica, se gesta la oportunidad de un renacer que se opone a la consideración del paso del tiempo como un "abismo que avanza" (669). Más bien, se gesta a partir de esta poesía otra posibilidad, otra manera de entender el tiempo más allá de la suma de desgracias que implica su pasaje. La poesía, desde ese momento, significa la posibilidad de un renacer que se distancia y se opone a la idea del tiempo como sucesión de momentos infelices. La poesía ocuparía el lugar de la permanencia y, en este sentido, reaparece una figura propia de esta poética, que es el cangrejo. Este animal funciona como un enmascaramiento del poeta, porque su presencia siempre está rodeada de la pérdida y de la imposibilidad de la escritura en un contexto donde prima el tiempo destructivo. Sin embargo, en el cangrejo también se congrega la posibilidad de la escritura; en el caminar y en el mirar hacia atrás se reconoce el pasado y, en consecuencia, la materia poética justifica su existencia. "A sabiendas" vuelve a reconocer la labor del poeta porque valora, ya desde el título, que uno de los lugares del saber reside en él: "Toda la noche escribe el cangrejo en la arena húmeda / El poema infinito de los mares" (671). La estrofa siguiente funciona como su antítesis porque muestra la otra faz del tiempo, el demoledor, marcado por el momento particular del día en el que la escritura será anulada por la fluidez de las olas: "Lo hace aunque sabe que al atardecer / Vendrán las olas a borrar su escritura" (671). Por momentos, también aparecen las limitaciones del trabajo poético, cuando las palabras no son suficientes; lo inefable se apodera del poeta y lo deja mudo:

Miseria,

Incurable miseria la poesía:

Intentar un poema que describa

A qué sabe el sabor del agua. (684) 
El testimonio de la muerte, tal como lo indicamos en el apartado anterior, es más evidente, hasta tal extremo que, como dicen los versos de "El arte del estrago", "los restos de las ruinas se hallan sujetos a la corrosión del tiempo" (759). El yo lírico es más consciente de que, a medida que pasa el tiempo, él se encuentra más cerca de ella. Las expresiones poéticas, entonces, parecen ser testimonios de esa proximidad que entendemos que no es deseada; más bien, el poeta desea mantenerse alejado de la muerte porque sabe que significa tanto su fin como el de su poesía. La muerte, simbolizada por la imagen del desierto, es el fin de un recorrido hacia donde todos vamos. El deíctico final del poema "Desierto", enfatizado por los dos puntos antepuestos, nos traslada nuevamente a ese título que no hace más que graficar el destino de los hombres:

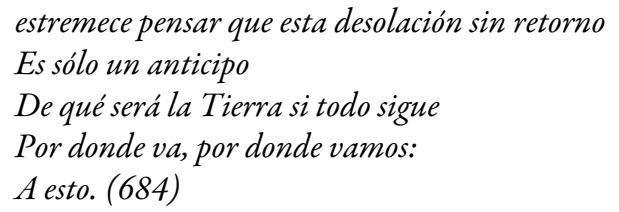

La sección "La cena de las cenizas" reúne algunos poemas donde el yo lírico abandona el rasgo que tiene la poesía de captar el instante; la ubica como una expresión que también accederá a la desaparición y al olvido. El poeta, en consecuencia, también se desvanecerá y un testimonio de ello es "Aduana", poesía que representa el encuentro entre la Muerte (en mayúscula, porque su presencia se personifica) y el poeta, quien, mediante un diálogo que muestra su sometimiento y obediencia, se resigna y renuncia a aquella que se le presentó con su "arrogancia de todopoderosa" (685):

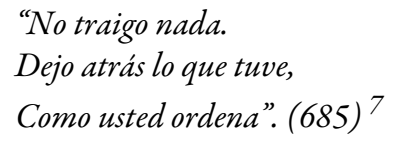

En otros momentos, ese yo poeta se desdobla y se encuentra con su versión ya anciana y, como explicamos, se establece un diálogo donde el otro (más viejo) "reemplaza” al más joven. Sin embargo, una mirada esperanzadora acompaña las dos estrofas que componen el texto porque esa cita implicó una espera que no supuso una decepción o desencanto, sino una continuidad que, si bien, como lo dice el verso final, "mi antiguo ser ahora ya es su fantasma" (686), el otro (ahora el joven) pervivirá en el nuevo yo: "De hoy en adelante él será yo" (686). La contigüidad con la Muerte también se resignifica cuando se la opone con la Vida, precisamente, cuando el poeta, continuando con un tono pesimista frente al destino de su poesía luego de su deceso, reelabora un diálogo ficcional entre la Vejez y la Vida en un contexto trivial en el que, como versa el título, ellas están a la espera de "la hora de todos":

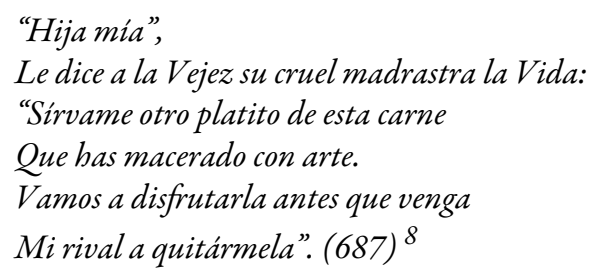

La poesía, de acuerdo con estas últimas lecturas, sería lo que no permanece, lo que pertenece a todo ese conjunto de cosas que, según los versos de "En la estación final", "se viene abajo y se despide" (687) porque el mundo dice "Ya no eres de aquí, / No te reconocemos como nuestro. / Lo que creíste como tuyo era sólo un préstamo" (687). Sin embargo, es en un conjunto de poemas de La edad de las tinieblas [2009] donde la expresión poética recupera su ímpetu de permanencia, donde es capaz de hacerle frente al caos y justificar su presencia. Así, “Despoblación”, poema en prosa compuesto por dos párrafos, ciñe dos momentos y, más allá de la contraposición que plantea, exhibe el valor de la palabra. La voz poética, entre "papeles destruibles" (747), 
halla una "agenda remota" (747) que hace presente la ausencia porque ese archivo recupera la "necrópolis de las ausencias y los afectos perdidos" (747). La agenda, entonces, muestra los restos de quienes no están y de los lugares que nunca más se visitarán, "la deshabitan personas de otras épocas y otros lugares. Unas cuantas siguen aquí a la distancia de algunas calles, un número telefónico o una dirección de Internet — pero en sitios que no volveré a ver, recintos adonde no hay retorno posible-" (747). Sin embargo, el segundo párrafo restituye, de diferentes maneras, esas ausencias mediante "una parte edificante" (747) y ahí es donde aparece, como sobreviviente "en el zafarrancho general de la vida, en la guerra perpetua y la separación interminable" (747), la palabra poética que se pronuncia en el mismo momento en el que se recuerda "el segundo de amor, el minuto de acuerdo, el instante de amistad" (747).

La referencia a la "parte edificante" (747) como particularidad del arte poético, o bien de la escritura en general, se presentará en "Un ritual” como elemento clave de la reflexión metapoética que incluye el texto. Este poema se puede leer como una referencia del propio Pacheco sobre su trabajo como poeta; incluye una manera de pensar y realizar la actividad lírica que se acerca a su trabajo como escritor. Así, la referencia inicial a Alfonso Reyes ya define una forma de posicionarse frente a una tradición que Pacheco pretende recuperar. La mención de su maestro para rescatar "un ritual masoquista inventado por los asirios" (765) coloca a Reyes en un lugar de relevancia que implica un gesto de gratitud. Este ritual hace referencia a la práctica de la escritura-reescritura que siempre pregonó como uno de los principios de su poética, así, el siguiente fragmento parece ser una definición de su modo de trabajar y considerar su escritura, sostenida mediante el esfuerzo y el compromiso continuo que, sin embargo, parecen ser siempre insuficientes:

Ningún arte llega a aprenderse de verdad. Hasta en la disciplina practicada a diario desde edades tempranas hay siempre fallas, errores, movimientos en falso que se pagan con sangre. Inútiles la experiencia, el aprendizaje, la constancia, la técnica, la atención, el cuidado: como la página perfecta, la absoluta lisura no se alcanza jamás, aunque el cartucho de varias hojas se lleve jirones invisibles de piel y abra heridas microscópicas.

No importa el tiempo invertido. Así como en el texto mil veces revisado saltan los errores cuando ya no hay remedio, al terminar de afeitarse nunca falta un sector impune, una leve maleza irreductible a las navajas. (765)

El uso de la primera persona del singular revela el posicionamiento del yo como escritor y de su labor como un proceso que, a pesar de sus faltas o de los restos que produce esa "tarea interminable" (765), perdura en el mismo proceso de reescritura, de perfeccionamiento de la palabra literaria. Es desde esa reflexión, tenaz e inquebrantable, sobre la palabra poética que se entiende el compromiso del poeta hacia su poesía: "El ritual cotidiano deja una enseñanza: la verdadera recompensa del trabajo es el placer que hay en intentar hacerlo bien, aun a sabiendas de que en poco tiempo nuestro esfuerzo será inútil y habrá que recomenzar a partir de cero" (765). La celebración del instante reaparece cuando el lector se dispone a leer la poesía que el poeta tanto releyó y reescribió. Así, "Los versos de las calles" constituyen un reconocimiento a quien posa su interés sobre ellos, los cuales, en su mayoría, son víctimas del desinterés y la apatía: "Los veo formarse indefensos y salir en busca de alguien que los resguarde. La inmensa mayoría les da la espalda. Cuando ellos se acercan las personas desvían la mirada y hacen como si los versos no existieran" (767). Mediante el procedimiento de la personificación, el yo lírico acentúa la materialidad de su trabajo y esto no hace más que reforzar la indiferencia poética: "En su desamparo los versos se drogan aspirando la Nada y se quedan inertes en la esquina. Algunos se dan el valor para entrar en lugares públicos. Tampoco allí los toman en cuenta y el personal los expulsa de mala manera" (767). Sin embargo, el poema que cierra La edad de las tinieblas [2009], que se titula "La plegaria del alba”, se aleja del tono pesimista y desalentador sobre el destino de la poesía para ceder su espacio a una posibilidad que identifica la juventud de un día que comienza con el posible renacer de un nuevo mundo. Este recomenzar "anula nuestra desesperanza, nos absuelve de nuestra locura, comprueba que el mundo no se disolvió en las tinieblas como hemos temido a partir de aquella tarde en que, desde la caverna de la prehistoria, observamos por vez primera el crepúsculo" (773). La poesía no está ausente, no es el "sector vulnerable al que han vencido" (657), sino que, aun enfrentándose una y otra vez a diferentes formas de fracaso, resucita en cada amanecer que "nos entrega la primera hora y el primer ahora de otra vida" (773). La poesía, entonces, y 
particularmente en el poema "Sombra de nieve", se sostiene en el lenguaje y el lenguaje en la posibilidad de un renacer porque, como dicen sus versos, "resuelve / La desunión, la discordia" (667).

\section{Conclusiones}

En la imagen poética de la ruina reside una de las posibles entradas al universo poético de José Emilio Pacheco; su identificación como figura clave en el proyecto literario de este escritor se articula con las diferentes inflexiones que adquiere en los distintos poemarios. Mientras que en Los elementos de la noche [1958-1962] la ruina se sostiene a partir de una perspectiva general y universal, en El reposo del fuego [1963-1964] se la vincula con la exhortación a los pueblos aniquilados y desaparecidos. Ya en el poemario Miro la tierra [1984-1986], la voz lírica se construye desde la experiencia concreta del desastre, por lo tanto, la ruina se enlaza con la tragedia provocada por el terremoto ocurrido en la ciudad de México en 1985. El poeta, de este modo, se enfrenta al desastre y plasma su experiencia mediante la escritura.

La tríada ruina, destrucción y ceniza continúa presente en los últimos proyectos poéticos de Pacheco, acompañando, en este caso, los sentimientos de desazón y soledad frente a un mundo cada vez más plagado por los restos de una sociedad en constante derrumbe y atestada por la suciedad provocada por los hombres. Frente al desastre, el yo poético parece no reconocer una posibilidad de salvación, parece no conocer otro destino fuera de los resabios que deja la tragedia; sea esta universal, indefinida, o bien, particular, situada en momentos específicos de la historia. Nada está a salvo de las inevitables marcas del pasado; omitirlas, silenciarlas, es tarea inútil. Ellas siempre están ahí, reaparecen en la poesía y el poeta las enfrenta para entenderlas, advertirlas y comunicarlas. No obstante, como observamos en los últimos poemarios, a pesar de las reiteradas imágenes de la ruina, la destrucción y la inminente presencia de la propia muerte, el hablante poético se reafirma en las posibilidades de trascendencia de la palabra poética y, desde allí, enuncia su presencia.

\section{Referencias}

Benjamin, Walter. Conceptos de filosofia de la historia. Agebe, 2011.

Cristóbal, Vicente. "Precedentes clásicos del género de la oda". La oda. La poesía del Siglo de Oro. Géneros y Modelos, dirigido por Begoña López Bueno, Universidad de Sevilla, 2008, pp. 19-45.

García Montero, Luis. "La inmovilidad del movimiento. Poética de José Emilio Pacheco". Cuadernos Hispanoamericanos, n. ${ }^{\circ} 784,2015$, pp. 2-13.

Hutcheon, Linda. "Ironía, sátira, parodia. Una aproximación pragmática a la ironía". De la ironía a lo grotesco (en algunos textos literarios hispanoamericanos), editado por María Christen Florencia, et al., Universidad Autónoma Metropolitana, 1981, pp. 173-193.

Jitrik, Noé "Rehabilitación de la parodia”. La parodia en la literatura latinoamericana, coordinado por Roberto Ferro, Instituto de Literatura Hispanoamericana / Universidad de Buenos Aires, 1993, pp. 13-29.

Kamenszain, Tamara. La edad de la poesía. Beatriz Viterbo, 1996.

Manrique, Jorge. Coplas a la muerte de su padre. Castalia, 1983.

Monteleone, Jorge. El fantasma de un nombre. Poesía, imaginario, vida. Nube negra, 2016.

Pacheco, José Emilio. Tarde o Temprano [Poemas 1958-2009]. Tusquets, 2010.

Ruisánchez Serra, José Ramón. "La relectura como ética: contracatacresis en la poesía de José Emilio Pacheco". Pasión por la palabra. Homenaje a José Emilio Pacheco, coordinado por Edith Negrín y Álvaro Ruiz Abreu, Universidad Autónoma Metropolitana / Universidad Nacional Autónoma de México, 2013, pp. 155-165.

Ruiz Pérez, Pedro. "La oda en el espacio lírico del siglo XVII". La oda. La poesía del Siglo de Oro. Géneros y Modelos, dirigido por Begoña López Bueno, Universidad de Sevilla, 2008, pp. 277-318. 
Zanetti, Susana. "Perduración de la poesía en José Emilio Pacheco”. Estudios, vol. 18, n. ${ }^{\circ}$ 36, enero-junio de 2010, pp. 33-54.

\section{Notas}

* Artículo de reflexión.

1 Es posible vincular este interés por la imagen poética de la ruina con la novena tesis sobre la historia de Walter Benjamin, que describe un cuadro de Paul Klee que se llama Angelus Novus y en el que se plasma, como dice el filósofo alemán, el deseo del "ángel de la historia" de contemplar el pasado, "sus ojos están desmesuradamente abiertos, la boca abierta y extendidas las alas" (9). Las ruinas no se ocultan, se presentan frente a los ojos de su observador que, a diferencia del resto, no ve "una cadena de datos" (9), sino "una catástrofe única que amontona incansablemente ruina sobre ruina, arrojándolas a sus pies" (10). No se puede frenar, le es inadmisible parar, detenerse y recoger esos restos. Es la imposibilidad la que se le presenta; remediar la ruina es su deseo, sin embargo, se convierte en un desafío ilusorio. Observar la ruina, en efecto, se convierte en el único ejercicio posible; su "intervención" se limita solamente a observarla.

2 Consideramos que a partir de El reposo del fuego [1963-1964] (1966), segundo libro de poesías, se enfatiza la preocupación sobre la muerte porque los elementos de la naturaleza, como el fuego y el agua, se convierten en símbolos puros, representativos de la permanencia y el cambio constantes. A partir de los postulados de la filosofía presocrática, Pacheco comienza a delinear en la imagen del fuego la estampa de un mundo en constante mutación, una hoguera que contiene una inscripción ominosa sobre el destino de los hombres; las palabras, según los versos contenidos en dicho poemario, no son suficientes, no alcanzan para evitar el arribo del desastre porque "nada se restituye ni devuelve / el verdor a la tierra calcinada" (19).

3 Tamara Kamenszain aborda la relación entre poesía, sujeto y muerte en el ensayo "La lírica terminal", incluido en el libro La edad de la poesia (1996) y que luego fue editado en Historias de amor ( $Y$ otros ensayos sobre poesía) en el año 2000. La "lírica terminal" hace referencia al momento último de escribir la muerte o de escribir contra ella a partir de un conjunto de poemas, cuyos autores (Enrique Lihn, Néstor Perlongher, Héctor Viel Temperley y José Lezama Lima) son víctimas de enfermedades terminales. Si bien en la última poesía de José Emilio Pacheco no hay marcas o indicios de una representación de una enfermedad de tal característica, creemos que esto sí se sostiene en la disolución inexorable del sujeto lírico.

4 La muerte igualadora es un tópico clásico de la poesía desde la Edad Media a partir, por ejemplo, de las mencionadas Coplas a la muerte de su padre de Jorge Manrique: "Nuestras vidas son los ríos / que van a dar en el mar, / qu’es el morir; / allí van los señoríos / derechos a se acabar / e consumir; / allí los ríos caudales, / allí los otros medianos / e más chicos; / allegados son iguales / los que viven por sus manos / e los ricos" (48). José Emilio Pacheco continúa y ubica su poesía en esa tradición literaria occidental mediante la actualización del tema de la muerte como niveladora de las diferencias que en la vida son inevitables.

5 Jorge Monteleone en El fantasma de un nombre. Poesía, imaginario, vida (2016) aborda el estudio de diferentes poéticas, como la de Sthéphane Mallarmé, Charles de Soussens, Macedonio Fernández, Juan L. Ortiz, Silvina Ocampo, entre otras, a partir de una pregunta que se formula, parafraseando a Samuel Beckett, al inicio de su libro: ¿dónde y cuándo y quién es un poeta?, o bien, ¿quién dice "yo" en el poema cuando el poema dice "yo"? Monteleone, recuperando algunos de sus estudios críticos previos, se pregunta por los modos en los que se constituye el sujeto imaginario del poema y, para ello, rescata su vínculo con la figura del autor a partir de las ambivalentes relaciones con la experiencia vivida. La paradoja sostiene esta relación: la constitución de la subjetividad se sitúa entre la forma vacía del pronombre personal (¿quién dice "yo"?) y la mortalidad, que sitúa la enunciación poética como testamentaria, "una verdadera memoria de ultratumba" (15). En efecto, la hipótesis que atraviesa cada uno de los ensayos presentes en el libro es que la subjetividad en la poesía está condicionada y transfigurada por el termino insoslayable de la muerte: "Acaso porque decir yo es decir, a la larga, una frase testamentaria, el habla de un muerto futuro que ya lo es en toda escritura. Una frase cuyo horizonte final es vaciarse del sujeto que la nombra" (15).

6 Pedro Ruiz Pérez en "La oda en el espacio lírico del siglo XVII" plantea un sistema de oposiciones estructurales entre diferentes manifestaciones estéticas, como la oda, la elegía, la epístola, la sátira y la canción. Así, en el plano métrico, la oda se particulariza por la tendencia a la estructura estrófica y formas aliradas. Ya en el plano de la enunciación, la oda define a un emisor marcado y un receptor idealizado que mantienen una relación de respeto (281-282).

$7 \quad$ Las comillas se encuentran en el original.

8 Las comillas se encuentran en el original.

\section{Licencia Creative Commons CC BY 4.0}

Cómo citar este artículo: Pascual Battista, Rosario. "La figuración poética de la ruina en la última poesía de José Emilio Pacheco". Cuadernos de Literatura, vol. 25, 2021. https://doi.org/10.11144/Javeriana.cl25.fpru 